\title{
DOCUMENTOS
}




\section{DOCUMENTOS DO ARQUIVO HISTÓRICO DO RIO GRANDE DO SUL (Correspondência do Consulado de Espanha - Continuação)}

Com esta série conclui-se a publicação da correspondência do Consulado de Espanha em Porto Alegre e Rio Grande às diferentes autoridades, durante o período de 1837 a 1924, existente no Arquivo Histórico do Rio Grande do Sul.

Expressamos nossos mais sinceros agradecimentos ao diretor do Arquivo Histórico do Rio Grande do Sul, Moacyr Domingues e a seus funcionários, pelo auxílio e facilidades que a toda hora nos tem proporcionado, sem o que não nos seria possível a execução desta tarefa.

As transcrições paleográficas foram realizadas pelo professor e historiógrafo Moacyr Flores. 
(Anexo ao doc. de 20 de outubro de 1893)

Exmo Sñr Consul de España

El infra escrito, sudito Español residente en esta a capital, viene con la devida venia representar a V.E. contra el acto arbitrario de que fue victima en el dia 15 del corriente mes por parte de las fuerzas en operaciones en este Estado al mando del General de Brigada Dn. Artur Oscar de Andrade Guimaraes como pasa a esponer.

Siendo propietario de seis animales de raza propios para corridas en hipodromos, animales estos que componian la Coudeleria denominada Cuña situada en la Ciudad de Sam Leopoldo fueron arrebatados quatro de ellos por las fuerzas que componen la colunna al mando en jefe del Brigadier aque arriba me refiero y esto contra mi voluntad y contra lo que espresa la Constitucion Federal en su At -72 parrafo 17 confirmados en la Constitucion de este Estado At -71 parrafo 20.

Los animales arrebatados son los constantes del documento junto con el $\mathrm{n}-\mathrm{e}$ uno y son: Yegua doradilla, Minerva; medio sangre; Yegua Aguia, medio sangre; yegua Venus, tambien medio sangre y Yegua Stella puro sangre todos conocidos en los ipodromos de esta capital, representando un valor estimativo nunca inferior à treinta mil pesetas, lo que llevo a conocimiento de V.E. protestando por la cantidad desinnada daños perjuicios y demoras.

Dios Guarde V.E. muchos años

Porto Alegre, 18 de Obro 1893

Agapito Gonzales

(Anexo ao documento de 20 de outubro de 1893)

Primeiro Traslado

$\mathrm{L} \stackrel{\mathrm{O}}{\mathrm{n}} \stackrel{\mathrm{O}}{33}$ - Fs. n. $\stackrel{\mathrm{O}}{48}$

Escriptura de venda de animes de raça que fáz - João Augusto Schmitt a Agapito Gonzalez.

Saibam quantos esta publica escriptura de compra e venda virem, que no anno de mil oito centos noventa e trez, aos cinco dias do mez de Outubro, nesta cidade de Porto Alegre, Capital do Estado do Rio Grande do Sul, neste cartorio compareceram como vendedor João Augusto Schmitt e como comprador Agapito Gonzalez, ambos moradores nesta Cidade e os proprios que eu conheço e dou fé. E pelo vendedor foi dito ante as testemunhas adiante nomeadas e assignadas, que por esta escriptura vende ao comprador os seguintes animaes de raça que possue e se acham na coudelaria $=$ Cunha $=$ em São Leopoldo a saber: Egua douradilha = "Minerva" meio sangue, egua zaina = "Aguia" meio sangue - potrilho zaino $=$ Apollo - tambem meio sangue e filhos do reproductor Segonha, tendo estes animaes a seguinte marca: $S^{\lambda}$; egua alazã = Stella, puro sangue; egua 
tordilha - Venus, - meio sangue, filha do reproductor Emilio segundo com a marca $\Varangle$ e potrilho baio - "Neptuno" meio sangue filho do reproductor Chamberi, tanto este como a egua Stella não tem marcas. Que esta venda faz pela quantia de doze contos de reis, que neste acto recebeo do comprador em moeda corrente, a quem dá quitação do preço, garantindo por si seus bens presentes e futuros esta venda livre de duvidas e demandas transmittindo ao comprador todo o dominio, posse, direito e acção que sobre os referidos animaes tinha, para que elle dos mesmos se aposse e disponha como seus que ficam sendo em virtude da presente escriptura. Pelo comprador foi dito que aceita esta escriptura nos termos referidos e apresentou o bilhete de distribuição cujo theor é o seguinte: Ao 3 으 cartorio João Augusto Schmitt, vende a Agapito Gonzalez os animaes de raça denominados "Minerva, Stella, Venus, Aguia, Neptuno e Apollo, pela quantia de $12.000 \$ 000$ Em 5 de Outubro de 1893. P. Falcão. Assim justos me pediram esta notas o que fiz. Assim justos me pediram digo fiz. E sendo lhes por mim lida, e acharam conforme, aceitaram e assignaram com as testemunhas João Vieira Guimaraes e Abilio Correa Sá, também conhecidos de mim João de Oliveira Vianna tabelião interino que o escrevi e assigno Paga sello proporcional a quantia de 12:000\$0000. O tabelião interino João de Oliveira Vianna, João Augusto Schmitt, Agapito Gonzalez, João Vieira Guimaraes, Abilio C. Sá. Estavam quatro estampilhas no valor de doze mil reis devidamente inutilizadas. Traslado na mesma data.

Eu João de Oliveira Vianna, tabellião interino que o subscrevo e assigno em publico e razo

Em testemunho J. O.V. de Verd ${ }^{\mathrm{e}}$

\author{
O Tam. int $\stackrel{\text { - }}{ }$ \\ Jo d'Oliv $\stackrel{\text { a }}{\text { Vianna }}$
}

(Anexo ao doc. de 20 de outubro de 1893)

\title{
Publica Forma
}

Nós abaixo assignados declaramos e juizamos se preciso fôr ser verdade que no dia quinze do Corrente forão tirados da Coudelaria Cunha nesta Cidade pelas forças commandadas pelo General Arthur Oscar de Andrade Guimaraes, os seguintes animaes: Egua douradilha Minerva; egua zaina Aguia; egua alazã Stella; egua tordilha Venus; animaes estes de raça e pertencentes ao Senhor Agapito Gonzalez. São Leopoldo desoito de Outubro de mil oitocentos e noventa e tres. Guilherme Fahrion, Luis Sperb, Benito Maurel Veloso, Eduardo Bauer, Luis Jacob Sperb, Luiz Kersting, Germano Christiano Panitz, Frederico Scherer filho. Reconheço verdadeiras as oito assignaturas supra, do que dou fé. São Leopoldo desoito de outubro de mil oitocentos e noventa e tres. Em testemunho de verdade (estava o signal publico) 0 Tabelião Florencio da Silva Camara. Estavam tres estampilhas no valor de mil e oitocentos reis devidamente inutilisadas. Reconheço o signal e firma do Tabelião. Porto Alegre desenove de Outubro de mil oitocentos e noventa e tres. Em testemunho da verdade (estava o signal publico) $O$ Tabelião interino João de 
Oliveira Vianna. Estava uma estampilha no valor de duzentos reis devidamente inutilizada. Nada mais contem no documento que aqui bem e fielmente fiz extrahir a presente publica forma a cujo original em mão da parte apresentante me reporto e dou fé. Porto Alegre, desenove de Outubro de mil oitocentos e noventa e tres. Eu, João de Oliveira Vianna, tabelião interino que o subscrevo e assigno em publico e razo

Em testemunho Jo.O. V de Verd.

$$
\begin{gathered}
\mathrm{O} \mathrm{T}^{\mathrm{am}} \text { int }^{\mathrm{o}} \\
\mathrm{J} \text { 을 d'Oliv }- \text { Vianna }
\end{gathered}
$$

\section{Copia}

Illmo Señor Gerente do Prado Rio Grandense

$\mathrm{O}$ abaixo assignado para fins convenientes precisa que V.S. se digne passar lhe por certidão por ordem de quem foi inscripta a egua Minerva no pareo $7 \underline{0}$ effectivado no Prado Rio Grandense do qual V.S. e digno Gerente - no domingo 10 do corrente e mais se gagnou: qual o lugar? Caso afirmativo qual premio gagnou? - quem recebeu o premio? (Sello de 200 reis) Porto Alegre, 11 dezembro 1893

\section{Agapito Gonzales}

Certifico que a inscripção da egua "Minerva" para o 7 pareo das Corridas effectivadas hontem no Prado Rio Grandense vem firmada com o nome de Osório Machado, tractador dos animaes do Cidadão Jacob Kraef filho; - que ho resultado do pareo coube a egua Minerva com como classificação o 2 - lugar com o premio de $200 \$ 000$ (Duzentos mil reis) que foi pago hoje ho signor Jacob Kraef filho.

Porto Alegre 11 de Dezembro de 1893

Assgn Joaq. A. Ribeiro-Director gerente do Prado

Rio Grandense

、

Copia

Ilmo. Snr. Gerente do Prado Rio Grandense

O abaixo assignado para fins convenientes precisa que V.S. se digne mandar the passar por certidão por ordem de quem foi inscripta a egua Minerva para as corridas 
effectuadas no Domingo 26 do proximo passado mes hos pareos 6 a 9 - Porto Alegre 2 de dezembro 1893

(Sello de 200 reis) Agapito Gonzales

Joaquim A. Ribeiro- Gerente do Prado Rio Grandense

Certifico que nas corridas do dia 26 do proximo passado a egua Minerva foi inscripta no 6 e 9 pareo pelo cidadão Jacob Kraef filho.

Porto Alegre 2-12-93

assign Joaquim A. Ribeiro

Consulado de España

en Porto Alegre

Porto Alegre 19 de dezembro 1893

Excellencia

Tenho a honra de responder a nota de V.Exc do 7 de Novembro p.p.

$\mathrm{n}^{\mathrm{O}} 2860 .-$

Na conversação que tive a honra de ter con V.Exc. no dia 7 do corrente ja concordamos que ha questão do apoderamento dos cavallos de corrida do Sr. Agapito Gonzales não era conveniente adoptar os systemas empregados nas numerosas questões de tal genero, que V.Exc. declarou-me terem sido acceitos por outros representantes dos Governos Estrangeiros acreditados junto a V.Exc.

A questão levantada pelo Senhor A. Gonzales e quasi a unica no seu genero e alem disso em termos e circunstancias de tal modo excepcionaes - direi mesmo - de tal modo singulares - que uma prompta resolução e necessaria segundo a mais estricta justiça - E indubitavel que se ella faltasse poderiam originar se serias mas justas complicações.

Resumirei o facto - já conhecido de V.Exc.

Os quatro cavallos de corrida do Sr. Agapito Gonzales - Minerva - Venus - Aguia - e Estrella (veja- se o contracto regular lavrado nesta cidade - e apresentado em meu ultimo officio) foram requisitados em São Leopoldo por ordem do General Arthur Oscar de Andrade Guimaraes - pelos seus subordinados a protesto do direito de guerra serviço urgente do exercito - defesa nacional: os quatro cavallos - conforme o habito agora innegavel não foram pagos - comquanto pertencentes a um estrangeiro - nem foi deixado documento algum que podesse salvaguardar o direito do proprietario.

Os quatro cavallos requisitados pelo serviço de guerra - apos alguns dias - em quanto V.Exc. dignavase dirigirme a Nota do 27 de Novembro - eram conduzidos aos arredores desta Capital - mas não restituidos ao seu proprietário - achandose agora dois 
delles (Minerva e Venus) em nova Hamburgo na cavallariça do Senhor Jacob Kreff - e os outros (Aguia e Strella) em São Leopoldo - em poder dos Sñres Jose Antonio Cidade e José da Cunha.

Ignoro como aquelles cavallos achamse nos lugares citados e em poder dos senhores acima mencionados: mas o facto e que não só os cavallos estão detidos mas tambem os fizeram correr nos Prados desta Capital; - obtendo um delles no domingo passado um premio como os demonstram os documentos cuja copia envio inclusa.

Os commentarios são inuteis: - os quatro cavallos tomados pelo Governo - por ordem de um dos representantes da Auctoridade militar - achamse em poder de particulares - os quaes utilisamse delles na sua qualidade especial de cavallos de corridana presença e com o conhecimento de seu proprietario defraudado e da Auctoridade consular que representa o Governo de S.M. o rei de Espanha a qual já apresentou a V.Exc uma reclamação anterior a esse mesmo respeito.

Deixo a V.Exc. julgar acerca da oportunidade de punir severamente os auctores do que pode chamarse um crime: - soldados ou officias que mereciam uma bem grave punição.

E inutil que eu exija o que espero que V.Exc. mesma reconhecerá justo ordenar: - a restituição immediata dos cavallos ao seu proprietario e uma justa indemnisação ao mesmo proprietario quer pelos damnos causados a cavallos delicados e de sangue maltratados talvez na viagem - violentamente tomados - quer pelos prejuiços aos quaes o proprietario deveu submetter se não podendo utilisar os cavallos que - em proveito de outrem - alcaçavam premios.

Para marcar a somma da indemnisação - rogarei a V.Exc. queira nomear commissarios que se portam de accordo com os outros serão nomeados por este Real Consulado: - resolvendo em caso de não haver accordo entre os commissarios sejam nomeados arbitros por V.Exc. e por este Real Consulado. Pareceme esta proposta satisfactoria sob todos os pontos de vista - e que não poderá deixar de ser acceita por V.Exc.

$\mathrm{O}$ que rogo a V.Exc. e que a decisão deste assumpto haja a maior e mais urgente solicitude - da opportunidade da qual e inutil que demonstre a necessidade mais absoluta.

Espero de V.Exc. uma resposta que me permitta referir ao meu Governo - ja informado do succedido.

Aproveito a occasão para reiterar a V.Exc os protestos da minha mais alta consideração

Dios Guarde a V.Exc muchos años

El Consul int. ${ }^{\text {no }}$ de España

\section{A Sua Excellencia}

\section{Lencisa}

o Dr. J.P. de Castilhos

Presidente do Estado do Rio Grande do Sul 
Vice-Consulado de España en Rio Grande del Sur, 22 de junho de 1893

N. 21

Recebi el oficio de V.Exa fechado en 15 del presente mas, comunicandome haber espedido las necesarias ordenes para mi reconocimiento en el caracter de Vice Consul interino de España en este Estado.

Quedé

impuesto, y estoy en posesion de dicho cargo

Dios Guarde a V.Ex

José Mena

Exmo Sñr Dr Presidente de este Estado

Exmõ Sr: Presidente de este Estado

de Rio Grande do Sul Don Julio P.

de Castilhos

\section{Exmõ Senõr:}

Tengo el honor de levar á V.E. para los devidos efectos el Execuatur concedido por S.E. el Sr: Presidente de la República á mi nombramiento de Vice Consul de Espanã en esta ciudad.

En el desempeño del honroso cargo con que me distinguió S.M. la Reina Regente de España, espero de S.E. toda proteccion y que transmita las ordenes oportunas para definitivamente que dar reconocido por las Autoridades de ésta localidade

Aprovecho la oportunidad de manifestar á V.E. la seguridad de manifestar á Dios le guarde muchos anõs

Sant'Anna do Livramento 25 de Noviembre de 1893. 
Vice Consulado Español en San Borja

15 de Marzo de 1893

Exmo. Sr.

A su debido tiempo recivi la Comunicacion n. 409 que V.E. se ha servido remitirme avisandome haber dado las ordenes necesarias para mi reconocimiento de Vice Consul Español en esta Ciudad y su Distrito por Avizo del Ministerio de Relaciones Esteriores.

Aceptad, Exmo Sr. mi sincero reconocimiento, y permitidme asegurarvos el mas decidido esfuerzo por la justicia y equidad que exigen las circunstancias, y por la confraternidad y buenas Ralaciones que conservan ambas naciones

Dios gde a V.E. m. $^{\mathrm{s}} \mathrm{a}$.

Exmo Sr. Dr. Julio Prat de Castillo

Presidente del Estado de Rio Grande del Sud

\author{
Eduardo Ogaya \\ Vice Consul Español
}

Vice Consolato

di Spagna

Porto Alegre 5 febbrajo 1894

Eccelenza,

Questo Real Vice Consolato di Spagna attende ancora un ........ di riscontro alla sua nota del 19 Dicembre 1893 concernente il sequestro di quattro cavalli di valore, di proprietá del Sig. Agapito Gonçales, in circostanze del tutto speciali.

Adesso, a richiesta dello stesso Sig. Gonçales, il quale si reca ogni giorno in questo officio per sapere a che punto si trova il suo affare un pregio di far tenere qui nuita all'Eccellenza Vostra copia di tre ciertificati dai quali risulta che, nel solo mese di Settembre 1893, il solo cavallo Minerva ha guadagnato in premi di corsa la considerevole somma di $\$ 1.960 \$ 000$, somma che il vero proprietario del cavallo vitime nollo ragio, nevolmente, essendogli dovuta insieme con tutto il resto, principale ed assessorio, chi egli ha diritto di avere

Gradisca, Eccelenza l'espressione del mio profondo osseguio

L'Incaricato

(in asscupo del marchese Lencisa)

Gherardo Pio di Savoia 


\section{Tradução}

Vice Consulado de Hespanha Porto Alegre, 5 de Fevereiro 1894

Ex.

Este Real Vice Consulado de Hespanha ainda aguarda a vossa resposta à sua nota de 19 de Dezembro de 1893, acerca do sequestro de 4 cavallos de preço propriedade de Agapito Gonçalves, em circunstancias inteiramente especiaes.

Por isso, a pedido do proprio Sr. Gonçalves que todos os dias vem a esta repartição indagar do andamento da reclamação consular sobre este assumpto, vos envio junta a esta nota copia de tres certidões donde resulta que só no mez de Set ${ }^{\text {bro }}$ de 1893 e só o cavallo Minerva ganhou de premio de corridas a consideravel quantia de 1:960\$000, quantia q. o proprietario do cavallo reclama, com toda a razão, sendo-lhe devida com o demais, p. capital e juros (accessorio? ) que elle tem o direito a haver

Acceita , Exc ${ }^{\mathrm{a}}$ a expressão do meu mais profundo acatamento

O Encarregado

(Na auzencia do marquez Lencisa)

Gherardo Pio de Saboia

Vice Consulado de España

en Porto Alegre, 5 de Febbraio de 1894

IIl ${ }^{\mathrm{mo}}$ Snr Gerente do Prado "Navegantes"

$\mathrm{O}$ abaixo assignado para fins convenientes percisa que V.S. lhe certifique quantos premios forão ganho pella egoa "Minerva" no mez de Setembro do anno de 1893 e qual o seo valor.

Porto Alegre 9 de Janeiro de 1894

\section{Agapito Gonzales}

Attesto que revendo o livro de recibos de premios pagos da Sociação Prado Navegantes consta o seguinte:

Que a dez de Setemibro de mil oitocentos e noventa e tres a egua Minerva no 8 은 pareo ganhou o premio de primeito lugar no valor de quinhentos e cincoenta mil reis 
(550\$000) que foi pago ao proprietario João Augusto Schmitt e por ser verdade passo o presente que assigno

Porto Alegre 10 de Janeiro de 1894

o Gerente

Santiago D'Araujo

Per copia conforme all'originale conservato

in atti

Porto Alegre, 5 febbraio 1894

l'Incaricato

Gherardo Pio di Savoia

Vice Consulado de España

en Porto Alegre 5 de Febbraio de 1894

III $^{\mathrm{mo}} \mathrm{Sr}$. Gerente do prado Riograndense

O abaixo assignado para fins convenientes percisa que V.S. Ihe certifique quantos premios ganhou a egoa "Minerva" no mez de Setembro de 1893 e qual o seu valor.

\section{Porto Alegre, 9 de Janeiro de 1894 \\ Firm.: Agapito Gonzales}

Eu abaixo assignado certifico que, rivendo o livro de premios do Prado Rio-Grandense, d'elle consta que no mez de Setembro de 1893, a egoa "Minerva apenas ganhou un premio de primeiro lugar no valor de quatrocentos e quarenta mil reis $(440 \$ 000)$ nas corridas realisadas a 17 d'aquelle mez.

P. Alegre, 11-1-94

firm: Joaquin A. Ribeiro

Director - geral do Prado Rio Grandense

Per copia conforme all'originale conservato al atto

Porto Alegre, 5 Febbraio 1894

L'Incaricato

Gherardo Pio di Savoia 


\section{VICE CONSULADO DE ESPAÑA}

en Porto Alegre, 5 de Febbraio de 1894

$$
\text { Ill }^{\text {mo }} \text { Snr. Gerente do prado Boa Vista }
$$

$\mathrm{O}$ abaixo assignado para fins convenientes percisa que V.S. lhe certifique quantos premios ganhou a egoa "Minerva" no mez de Settembro de 1893 e qual o seu valor.

Porto Alegre 9 Janeiro 1894

firm: Agapito Gonzales

Certifico que tirou dois premios a egoa "Minerva" no mez de Setembro de 93, nas corridas effectuadas pela associaç̧ão do prado Boa Vista no valor de \$970\$000.

Porto Alegre, 10 de Janeiro de 1894

O Gerente

firm. M. Minaberry Junior

Per copia conforme all'originale

conservado in atti

Porto Alegre, 5 Febbraio 1894

L'Incaricato

Gherardo Pio di Savoia

R. Vice Consulado

de España

№ 21

Porto Alegre 30 Maggio 1894

Eccellenza

La Legazione di Spagna in Rio di Janeiro alla quale - secondo le istruzioni che ha ricevute - ha trasmesso una copia di tutte le note che sono state scambiate fra la Suprema Autoritá di questo Stato e questo $\mathrm{R}^{\mathrm{O}}$ Vice Consolato, circa il sequestro dei cavalli del Sig. Agapito Gonçales, mi ha indirizzata la nota che qui unita mi onoro di trasmettere in copia all'Eccellenza Vostra.

La Legazione di Spagna esprime il vivo desiderio che questa pendenza sia prontamente ultimata, ravvisando nell'indugio, non solo un danno gravissimo pel Sig. Gonçales ma quasi un offesa all'amor proprio ed al decoro dell'autoritá spagnuola accredita presso il Governo dell'Eccelenza Vostra. 
Io che conosco i sentimenti nobilissimi di cui Ella à animata, sono sicuro che nella sua alta saggezza troverá il modo di comporre, soddisfacentemente per tutti, questa questione, che dura giá da 8 mesi sebbene gli elementi per risolverla siano a portata di mano.

In me l'Eccellenza Vostra troverá il solito spirito di conciliazione e la solita deferenza.

Io sarei veramente felice se prima di lasciare questa residenza protessi per effetto della sapiente benevolenza dell Eccellenza Vostra, condurre a termine questo affare, secondo giustizia e secondo i sentimenti di fraternitá che uniseano i due nobilissimi paesi, il Brasile e la Spagna.

Col piu profondo rispetto

Il Console

Reggente il Real Vice Consolato di Spagna

Gherardo Pio di Savoia

A Sua Eccellenza

Dr. Julho de Castilhos

Governatore dello Stato di Rio Grande del Sud

Capitale

[Anexo ao doc. de 30 de maio de 1894]

№ 1

Copia

Ilmo Snr. do 3 으 Cartorio

O abaixo asignado precisa que lhe certifiqueis quaes as escrituras passadas no vosso cartorio de $1^{\mathrm{O}}$ de $\mathrm{Obr}-\mathrm{O}$ de 1893 a 15 do mesmo mez suas dactas e objetos vendidos. Porto Alegre 21 de Março 1894

Agapito Gonzalez.

Certifico que revendo neste Cartorio o Libro de transmissão de propriedades sob numero - trinta e trez = nelle d'folhas quarenta e seis á folhas cincoenta e quatro verso, se acham as escripturas de compras e vendas lavradas neste cartorio, desde o dia primeiro, digo desde o dia dous de Octubro a quatorz do mez referido de 1893 as quaes são as seguientes: Dia dous $=$ Dous terrenos que Felisberto Antonio da Maia e sua mulher fiseram venda a João Cesimbra Jaques, um terreno que Manoel Pereira de Azevedo e sua mulher venderam a Luiz Felippe Dortas do Amral $=$ Dia cinco $=$ Os animaes de nomes Minerva, Stella, Venus, Aguia, Neptuno e Apollo, que João Augusto Schmitt vendeu a Agapito Gonzelez $=$ Dia seis $=$ Um terreno que Serafim Ferreira de Magalhaes Rhodes 
vendeu a Luiz Monteiro da Silva. Um terreno que o mesmo Rhodes vendeu a Saturnino Antunes Pinto $=$ Dia nove $=U m$ terreno vendido por Israel Silva da Cunha a Alberto Fehlauer. Um terreno com um galpão que Joaquim Ferreira Prestes e sua Mulher ficeram venda a Joaquim Carvalho de Miranda, um terreno que Sergio Candido da Silva e outros venderam a Otto Drügg $=\mathrm{Dia}$ dez $=U \mathrm{~m}$ terreno vendido por Clemente José Ferreira Pinto a Paulino Pereira da Silva $=$ Dia treze $=$ Um terreno que João Sebastião Kraemer e sua mulher fiseram venda a Antonio Marques de Carvalho, um terreno que Bento da Silva Carneiro e sua mulher venderam a Antonio Marques de Carvalho, uma chacara que o Doutor Lopo Gonçalves Bastos e sua mulher venderam a Antonio dos Santos Rocha e a Julio Nectoux, um terreno que Luiz da Silva Nunez e sua mulher, venderam a Henrique Luiz Streocins $=$ Dia quatorce $=$ Um lanchão que Ignacio José Luix vendeu a Anterio Gomez Pires, uma caza que D. Adelaide Ferreira da Silva vendeu a Ignacio Montanha. Certifico mais que nos dias primeiro e quince de Octubro de mil oitocentos noventa e tres, não houve escriptura de compra e venda neste cartorio, bem como nos dias dentro do período de um a quinze daquelle mez e anno que deixaram de ser declarados na presente Certidão. Nada mais contem com relação ao pedido do suplicante e referido livro e folhas no principio declarados, em meu poder e cartorio, me reporto e dou fé. Porto Alegre 21 de Março de 1894. Eu, João d'Oliveira Vianna, tabelliao interino que o escrevi e assigno. O Tabellião interino João de Oliveira Vianna

V.B. para l̦egalizacion de la firma del

Escrivano publico João de Oliveira Vianna

Porto Alegre, 31 de Marzo 1894

El Consul interino de España

firmol Gherardo Pio di Savoia

V.B. Sta conforme al original

$\mathrm{El} \mathrm{Consul} \mathrm{interino}$

Gherardo Pio di Savoia

[Anexo ao doc. de 30 de maio de 1894]

№ 2

Recebi do Snr João Augusto Schmitt a quantia de tres contos de reis importancia pela qual lhe vendi a egua Minerva de minha propriedade. Porto Alegre, 5 de Octubro 1893. Saturnino Martins Velho.

V.B.

Il Vice Consulado de España

Porto Alegre, 31 Marzo 1894

El Consul interino

Gherardo Pio di Savoia 
[Anexo ao doc. de 30 de maio de 1894]

№ 3 Copia

Estancia da Brigadeira

Estado de São Pedro do Rio Grande do Sul

Município de Gravatahy

Declaro que vendi ao Snr João Augusto Scmitt

\begin{tabular}{|c|c|c|c|c|c|}
\hline Quantidade & Filiação & Idade & Pellu & Nome & Observações \\
\hline Uma Egua & Cegonha & Nasceu & Vermelho & Minerva & \\
meio sangue & $\begin{array}{c}\text { con Egua } \\
\text { peluda }\end{array}$ & $\begin{array}{c}\text { em 20 de } \\
\text { Obr. de } \\
1887\end{array}$ & & & \\
& & & & \\
\hline
\end{tabular}

Canoas 5 de Octubro de 1893. O Propietario

Saturnino Mathias Vello

V.B. Il Vice Consulado de España

Porto Alegre, 31 Marzo 1894

El Consul Interino

Gherardo Pio di Savoia

[Anexo ao doc. de 30 de maio de 1894]

№ 4

Copia

№ $162=$ P. S $\div$ B. ${ }^{k}$

Prado Rio-Grandense

O abaixo assignado participa ao Director-Gerente do Prado Rio-Grandense, afim de ser registrado no seu Stud-Book, o nascimento do produto de sua propiedade adiante dessignado- Nome Gravata. Sexo Feminino. Pello Tordilho. Signaes caracteristicos: . . . . . Nascido en Estancia - Serro. Municipio de Quarahy. Estado Rio Grande do Sul aos 6 de Janeiro de 1891. Filiação = Pae Emilio IIํ- por Cuatro versy e Emisca Mae 
Peluda. Porto Alegre 9 Junho 1892 por Victorino Monteiro Assunção Vianna. Este animal foi inscripto nos prados de Porto Alegre com o nome de Venus.

João Augusto Schmitt

V.B. Al Vice Consul de España

Porto Alegre, 31 de Marzo 1894

El Consul interino

Gherardo Pio de Savoia

[Anotação à margem:]

Eu abaixo assignado certifico que o producto constante da presente participação fica inscripto sob $\mathrm{n}-162$ a pagina do Stud-Book Rio-Grandense. Porto Alegre 30 de Junho 1892. O Director-Gerente Joaquim. A. Ribeiro

[Anexo ao doc. de 30 de maio de 1894]

N으 5

Copia

Bento Ribeiro recebeu do cidadão João Schmitt a quantia de (300\$000) trezentos mil reis de uma potranca 1/2 sangue que lhe vendeu en 23-5-93.

V.B. Al Vice Consulado de España

Porto Alegre 31 Marzo 1894

El Consul Interino

Gherardo Pio de Savoia

[Anexo ao doc. de 30 de maio de 1894]

№ 6

Copia

Recebi do Sñr José Antonio Cidade a quantia de um conto de reis importancia pela qual vendi ao mesmo Sñr a Potranca "Aguia", Zaina, meio sangue Cegonha. Porto Alegre 30 Julho 1893

Saturnino Mathias Velho

V.B. Al Vice Consulado de España

Porto Alegre, 31 Marzo 1894

El Consul interino

Gherardo Pio de Savoia 
[Anexo ao doc. de 30 de maio de 1894]

\section{№ 7}

Copia

Recebi do Sñr João Augusto Schmitt a quantia de um conto e quinhentos mil reis procedente da venda da egoa "Aguia", Zaina, meio sangue Cegonha, cujo animal esta no Stud-Book do Prado Rio-Grandense, e para saberse passei o presente. S. Leopoldo 15 de Setembro de 1893. G.A Cidade
Al Vice Consulado de España
Porto Alegre, 31 Marzo 1894
El Consul interino

Gherardo Pio de Savoia

[Anexo ao doc. de 30 de maio de 1894]

№ $8 \quad$ Copia

Certificado n으 183

Catarsalle Nacional

Carlos $\mathrm{M}^{\mathrm{a}}$ - Villanueva

Buenos Aires 12 de Setembro 1891

Certifico haver vendido al Sñr $D^{r}$ Adriano Nuñez Ribeiro los animales que a continuacion se espresan.

Um potranca alazana sangre pura de carrera "Stella" de la yegua "Hiveroor" y "Nill Sperari" puro importado com la siguiente marca y para su constancia espido el presente. Carlos M. Villanueva. Pedigree. Es pura sangre, Hiverror" es puro por mestizacion descendiente de "Vielle" y "Guerrero" nacida el 12 de Deziembre $1890=$ Vale

Al Vice Consulado de España

Porto Alegre, 31 Marzo 1894

El consul interino

Gherardo Pio de Savoia 
[Anexo ao doc. de 30 de maio de 1894]

№ 9

$$
\begin{aligned}
& \mathrm{N}^{\mathrm{o}} 28 \text { P. } \text { S. }^{\mathrm{d}} \mathrm{B}^{\mathrm{k}} \\
& \text { Prado Rio-Grandense }
\end{aligned}
$$

O abaixo assignado participa ao Director-Gerente do Prado Rio Grandense, afim de ser registado no seu Stud-Book o nascimento do producto de sua propiedade adiante designado.

Nome -Stella

Sexo Femenino. Pello Alazão

Nascido Estado de Buenos Aires

aos 12 de Dezembro de 1890

\section{Filiação}

Pae Nil Sperari

Mae Hiveroor por Gerreiro e Vielle. Porto Alegre 29 de

Junho de 1892 . João Antonio Schmitt
Al Vice Consulado de España
Porto Alegre, 31 Marzo 1894
El Consul interino
Gherardo Pio de Savoia

[Anotação à margem:]

Eu abaixo assignado certifico que o producto constante da presente participação fica inscrito sob o n- 28 a pagina 1 do Stud Book Rio-Grandense. Porto Alegre, 29 Junho de 1892

O Director -Gerente. Joaquim A. Ribeiro

[Anexo ao doc. de 30 de maio de 1894]

№ 10

Illm - Snr Gerente do prado "Navegantes"

O Abaixo assignado para fins convenientes percissa que V.S. se digne responder por certidão aos seguientes quesitos:

$1^{\circ}$ - Por quem foy inscrita a egua Stella para as corridas efectuadas en $12 \mathrm{de} \mathrm{Obr}^{\mathrm{O}}$ do ct. anno? 
20 En que lugar foy clasificada?

3을 Que premio lhe coube?

$4^{\circ}$ - Aquem foy pago o premio?

\section{P. Alegre, 4 Novembro 1893}

\section{Agapito Gonzales}

Em comprimento do seu abaixo assignado do di 4 de Novembro do corrente, cabe-me responder $=$ vos

1 음 Não consta no archivo deste Prado durante a minha gerencia os nomes dos inscricptores, e sim asinaturas dos que levantam premios.

em quantos os outros $\mathrm{Ar}^{\text {ㅇ }}$ a 12 de Outubro de 1893 Paguei o premio da Egua Stella na importancia de $200 \$ 000$ rs. duzentos mil reis ao Cidadão Agapito Gonzales , E por nada mais constar passo o presente que assigno.

Porto Alegre, 20 de Novembro de 1893

Santiago de Araujo

V.B. Al Vice Consolado de España

Porto Alegre, 31 Marzo 1894

El Consul interino

Gherardo Pio de Savoia

[Anexo ao doc. de 30 de Maio de 1894]

R. Vice-Consulado

de España

$\mathrm{n}-4$

Copia

Petrolis, 25 Avril 1894

A M? ${ }^{\mathrm{r}}$ Le Chevalier Pio de Savoia

Vice Consul d'Espagne a Porto Alegre

Monsieur

J'ail'honneur d'accuser reception de votre note du $1^{\circ}$ Avril, N\$ 8/6, concernant la reclamation de $\mathrm{M}^{\mathrm{T}}$. Agapito Gonzales propriétaire des 4 chevaux de courses sequestrés par 
les troupes du Général Arthur Oscar, ainsi que tous les documents que l'accompagne prouvant les droits de $\mathrm{M}^{\mathrm{T}}$ Agapito Gonzales; les ayants lû avec stricte attention, je reconnais dans les notes que vous avez reçu des Autorités qui refusent l'admettre la dite reclamation un sentiment de malveillance, bien marquée de leurs part pour tâcher d'empecher que justice soit faite a $\mathbf{M}^{\mathrm{r}}$ Gonzales.

Vouz avez toute mon aprobation pour les demarches que vous avez faites, et devez continuer à demander aussi fermememt que respectueusement que réparation soit fait d'apris justice. Vous pouvez compter sur tout mon appui.

Je n'arrive pas à comprendre comment le Sr. Fogaça se croit autorisé par ses Superieurs à se permettre de dénoncer une plainte de ce Consulat d'Espagne «comme une sordide spéculation sous pretexte d'assailir les fonds publiques à l'aide du pavillon étranger $\gg$; je ne manquerai pas d'en referir á $\mathrm{M}^{\mathrm{I}}$. de Nascimento me plaignant des attaques grossierès dirigés à la representacion de mon Gouvernement.

J'espere que S.E. M! de Castilhos que vous me représentez comme un homme supérieur, animé des meilleurs sentiments, reconnaîtra sans dificulté que le droit est de votre coté et que je recevrais de vous bientôt l'annonce d'une prompte et satisfaisante solution en faveur de $\mathrm{M}^{\mathrm{r}}$. Gonzales qui a tous les droits à exiger le remboursement des pertes ocassionnées par la séquestration de ses chevaux.

J'aime á croire que S.E. $\mathrm{M}^{\mathrm{r}}$ de Castilhos désaprouvera le zéle trop ardent du Sieur Fogace et que vous obtiendrez sans dificulté que les reclamations du Vice Consulat ne seront plus qualifiés par des non reçu que ni vous ni moi ne pouvons admettre.

Venillez agrecer, Monsieur, l'assurance de ma consideration la plus distinguée

firm.

Jose de Romero y Dusmet

Io sarei veramente felice se prima di lasciare questa residenza potessi, per effetto della spiente benevolenza dell'Eccellenza Vostra, condurre a termine questo affare, secondo giustizia e secondo i sentimenti di fraternitá che uniscano i due nobilissimi paesi, il Brasile, e la Spagna.

Col pui prefondo rispetto

Il Console

Reggente il Real Vice Consolato di Spagna

Gherardo Pio de Savoia

anexo ao documento 
Porto Alegre, aos 31 de Março de 1897

A sua Excellencia

O Dr. Júlio Prates de Castilhos

Presidente do Estado de Rio Grande do Sul

Capital

no9 $9 x$ Exellencia

Na ultima audiencia de Fevereiro findo, Vossa Excellencia sabendo que achava me incumbido da direcção deste Regio Vice-Consulado d'Espanha, aproveitava aquella occasião, informando-me que tinha recebido uma informação do Senhor Intendente Municipal de São Leopoldo, da qual resultava que a queixa do súdito Hespanhol, Agapito Gonzalez, objecto de anterior correspondencia, era completamente infundada.

A vista de uma tal declaração, como assitia-me o respeito para com Vossa Excellencia, e a ignorancia, na qual me achava, acerca do conteúdo da informação mencionada, limitei-me, a responder que me aguardava para conhecer os factos e as razões adduzidas pelo Senhor Intendente Municipal de São Leopoldo, e que se pelo exame dos mesmos, pudesse convencer-me que o Senhor Agapito Gonzalez tinha abusado da boa fé deste Regio Vice-Consulado, não deixaria de desistir de qualquer pratica ulterior em seu favor.

A informação do Senhor Intendente foi me communicada por copia, junto a respeitavel nota de 23 de Fevereiro de 1894, sob n- 293.

Vossa Excellencia me permittirá agora dizer toda a verdade, assim como eu penso, e conforme me impõe a tutela dos interesses que a confiança do Governo de Sua Magestade Catholica em mim depositou.

Examinei com a maxima diligencia e sem preconceitos a informação que o Senhor Epiphanio Orlando de Paula Fogaça, Intendente Municipal de São Leopoldo, dirigiu a Vossa Excellencia em data de doze de Fevereiro transacto, e não é sem grande admiração que tive de persuadir-me que aquella informação em nada justifica a improcedencia da queixa do Senhor Agapito Gonzalez, pronunciada por Vossa Excellencia e me foi communicada com a referida nota de 23 de Fevereiro ultimo.

O Senhor Epiphanio Fogaça julgando talvez dar provas de zelo e intelligencia, separando a causa do justo e honesto, d'onde, conforme seu modo de ver, seria o desejo do Governo não exitou em substituir as affirmações mais gratuitas aos factos, melhor documentados; e, o que é peior ainda, para offender gravemente com suas insinuações a honra de um regular numero de pessoas muito respeitaveis. 
Em resumo, o que o Senhor Intendente Municipal de São Leopoldo sustenta, é o que Vossa Excellencia em bôa fé me repetiu com a respeitavel nota de 23 de Fevereiro, isto é que o Senhor Agapito Gonzalez não passa d'um proprietario ficticio das quatro eguas Minerva, Venus, Aguia e Stella, o qual chama-se a posse na qualidade de proprietario por um contracto de venda simulada, e que o fim de uma tal simulação seria, o de obter do Governo uma gorda indemnisação, fazendo passar como proprietario das quatro eguas supra ditas, um hespanhol, quando ao contrario os proprietarios das mesmas, seriam o Senhor Coronel João Schmith, e o Senhor Saturnino Mathias Velho, cidadãos brasileiros.

São estas as affirmações do Senhor Epiphanio Fogaça; porém quaes fossem as provas, quaes os factos, e os documentos, sobre os quaes elles são fundados, ninguem o sabe e ninguem pode sabel-o; o mesmo Senhor Epiphanio Fogaça os ignora.

A unica affirmação, sobre a qual concordo, é de que os animaes que fôram sequestrados á 15 de Outubro de 1893 pelas forças do General Arthur Oscar de Andrade Guimarães, eram quatro eguaas e não quatro cavallos; não posso porém comprehender a emphase, com a qual o optimo Senhor Epiphanio Fogaça sustenta e repete uma cousa que nunca ninguem cuidou em negar. Quando ainda os nomes femininos de Minerva, Venus, Aguia e Stella, não indicassem claramente que se trata de eguas, a identidade das mesmas é estabelecidade com tamanha e tanta clareza, com tamanha precisão technica no acto de venda, da qual este Regio Vice-Consulado d'Espanha se honrava de transmitttir uma copia a Vossa Excellencia com a nota de 20 de Outubro de 1893, serião o sufficiente, para affastar todo o merecimento da descoberta do Senhor Epiphanio Orlando de Paula Fogaça.

Fique entretanto compehendido - sendo que o Senhor Intendente Municipal de São Leopoldo finge crêr o contrario - que este Regio Vice-Consulado nunca fallou, nem jamais se occupou de outros animaes equinos a não ser os supra ditos, e que não é sua culpa, se o Senhor Epiphanio Fogaça leva a sua má fé até ao rediculo, e se ignorando, ou fingindo ignorar, o espirito da lingua, na qual estão redigidas as notas precedentemente dirigidas a este Governo, tem crido ou fingido crer que os animaes equinos, isto é os cavalos: Minerva, Venus, Aguia e Stella, dos quaes tratava este Regio Vice-Consulado, não fossem as quatro eguas que fôram sequestradas pelas forças do General Arthur de Andrade Guimaraes.

Isto posto, apresso-me a entrar na questão.

O contracto estipulado nesta cidade a 5 de Outubro de 1893, pelo tabelião João de Oliveira Vianna, na presença das testemunhas: João Vieira Guimarães e Abilio Corrêa Sá, e em virtude do qual o Senhor João Augusto Schmitt vendia ao Senhor Agapito Gonzalez as quatro eguas Minerva, Venus, Aguia e Stella, como também os cavallos Apollo e Neptuno (estes dous ultimos não entram na presente questão) pela quantia 
complexiva de $\$ 12: 000 \$ 000$, comprova de modo indiscutivel que o proprietario das quatro eguas mencionadas, é o comprador das mesmas, Agapito Gonzalez.

Para negar o direito de propriedade do Senhor Agapito Gonzalez, sobre as quatro eguas mencionadas, não se podendo negar a existencia do contracto, precisaria ao menos que ja existisse uma sentença do tribunal que tivesse declarado ser falso o contracto; porem esta senteça ainda não foi pronunciada, e jamais poderá sel-a, sendo que nenhum dos interessados a fazel-a, atreveu-se, nem se atreverá atacar de falso semelhante contracto perante os tribunaes; não se atreverá o Coronel João Schmitt, o qual já tem declarado não ser elle o proprietario das quatro eguas, e que por isto mesmo recusou recebel-as, quando o Senhor Kroeff lh'as offerecia; não se atreverá João Augusto Schmitt, o qual firmou o contracto em questão e tem declarado, e está prompto novamente a declarar, ter vendido regularmente as quatro eguas ao Senhor Gonzales; nem o Senhor Saturnino Mathias Velho, o qual desde o dia 30 de Julho de 1893, passava a quitação do preço de Aguia, e desde o dia 5 de Outubro de 1893 o recibo do preço de Minerva; nem o Senhor Jacob Kroeff que contenta-se de desfructar o uso das eguas: Venus e Minerva, e de embolsar os premios que ellas vencem, sem allegar algum direito de propriedade sobre as mesmas; nem finalmente o governo, ao qual bastam as froças das quaes dispõe para não ter conta do artigo 72, § 17 da Constituição dos Estados Unidos do Brasil, e do artigo $71, \S 20$ da Constituição deste Estado.

O Senhor Epiphanio Fogaça portanto affirmando que se trata de uma venda simulada, e que o Senhor Agapito Gonzalez é simplesmente um proprietario ficticio, nada mais faz que offender inutil e gratuitamente a honra do Senhor João Augusto Schmitt (vendedor das quatro eguas), necogiante respeitabilissimo e favoravelmente conhecido em toda cidade; do Senhor Agapito Gonzalez (comprador), subdito hespanhol, pessoa honradissima, presidente da sociedade hespanhola de Beneficencia; dos Senhores João Vieira Guimarães e Abilio Corrêa de Sá (testemunhas), do Senhor João de Oliveira Vianna (tebelião), o qual cooperava para consumar um reato; do coronel João Schmitt, official da Guarda Nacional, o qual accedendo as insinuações do Senhor Epiphanio Fogaça, seria o mais interessado de todos na fraude; dos Senhores Saturnino Mathias Velho, José Antonio Cidade e Manoel José da Cunha, os quaes estão todos dispostos na esphera dos factos que estão a seu conhecimento, para testemunhar em sentido contrario, ao que sustenta o Intendente Municipal de São Leopoldo. O Senhor Epiphanio Fogaça com suas palavras mal medidas offende tambem este real Vice-Consulado, sendo que poderia-se julgar que ou por excesso de ingenuidade, ou para favorecer os intuitos malevolos de um grupo de trapasseiros, se induzisse a patrocinar perante Vossa Excellencia uma causa tão vergonhosa. 
O Senhor Epiphanio Fogaça finalmente ofiende outrossim, e ainda mais o Governo de Vosssa Excellencia que elle julgaria tão baixo na opinião publica, podendo ser considerado capaz de ceder com mais facilidade as pretenções de um estrangeiro, do que prestar homenagem a verdade e a justiça, no interessse de um counacional, o qual para tal fim teria recorrido ao indigno extratagema, de fazer passar, o que era seu, como de proprieda de um hespanhol.

Independentemente do desgosto que o animo nobre de Vossa Excellencia deve experimentar a presença de um funccionario governativo, o qual julga captivar a estima de seus superiores, affirmando gratuitamente uma cousa não verdadeira, para dar ao Governo o pretexto de commetter uma grande injustiça, em prejuizo de um honesto e laborioso estrangeiro, Vossa Excellencia que sabe com quanta parcimonia e com quanta demora o Governo procede em conceder indemnisações aos estrangeiros, ainda quando para isso tenham incostestavel direito, não pode fazer senão rir-se, quando o Intendente Municipal de São Leopoldo affirma que os Senhores Schmitt e Mathias Velho tivessem deixado sequestrar alguns cavallos de valor, e não quizessem recebel-os, quando queria-se a elles fazer a restituição, á esphera de uma indemnisação hypothetica, futura, cuja importancia, em todo o caso deveria ser fixada de combinação com o Governo.

Vossa Excellencia reflectirá tambem que o contracto effectuava-se aos 5 de Outubro de 1893 e o sequestro aos 15 do mesmo mez.

previram?

Os pretendidos autores e cumplices da venda simulada não podiam em consequência saber com certeza no dia 5 , o que devia acontecer no dia 15; em todo o caso não dependia que do General Arthur Oscar, e de seus dependentes para frustrar as previções d'elles, abstendo-se do sequestro dos cavallos completamente inuteis, ao fim para o qual deviam ser adhibidos.

Ainda quando os Senhores Gonzalez e Schmitt tivessem previsto a possibilidade, de que as quatro eguas iriam ser sequestradas, existe talvez alguma disposição legislativa, a qual impeça a um proprietario de cavallos de vendel-os em tempo de guerra civil, ou que inhiba a um estrangeiro de podel-os comprar? E poderia-se talvez censurar ao Senhor João Augusto Schmitt, se prevêndo a possibilidade do sequestro dos proprios cavallos, os vendesse ao Senhor Agapito Gonzalez, para não ser mais tarde obrigado, a fazer as praticas necessarias afim de ser indemnisado conforme o Artigo 72

da Constituição dos Estados Unidos do Brazil, e do artigo 71 da Constituição do Estado Rio Grande do Sul? Quem poderia dizer que as previsões dos Senhor Schmith fossem mal fundadas, depois do que tem acontecido, e do que acontesse ao infeliz comprador Agapito Gonzalez?

Das informações que colhi, parece effectivamente que o Senhor João Augusto Schmitt - bem sabendo que seu pae João Schmitt não está bemquisto do actual Governo, receiando que de um dia para outro, por odio a seu pae, lhe seriam sequestrados os cavallos que possuia, ainda que não fossem proprios para o serviço militar, e que teria encontrado não 
pequenas difficuldades para obter as indemnisações garantıdas pelas leis achava prudente desembaraçar-se dos mesmos em tempo, vendendo-os aos Senhor Agapito Gonzalez.

Este de sua parte deixava-se ainda com mais facilidade persuadir-se a compral-os, emquanto que, sendo elle subdito hespanhol, e tendo sempre tido uma conducta exemplar, nunca se tendo occupado com a politica do paiz; com razão firmemente julgava que ninguem o poderia molestar na posse pacifica de quatro animaes equinos, os quaes attendendo a delicatesa dos mesmos e o preço eram pouco indicados para serem adhibidos ao serviço militar.

Com razão o Senhor Gonzalez - em opposição a quanto deixa entender o Senhor Fogaça - sendo apaixonadissimo pelos cavallos e pelas corridas, de combinação com seu irmão, punha como condição ao Senhor João Augusto Schmitt de fazer entrar no contracto, o qual foi estipulado a 5 de Outubro ultimo findo, tambem a egua "Minerva" forte animal corredor, o qual por isto o Senhor Schmitt no mesmo dia adquiria do Senhor Saturnino Mathias Velho - o qual da mesma de boa vontade, livrava-se talvez com medo dos mesmos perigos supra mencionados - afim de vendel-a logo depois ao Senhor Gonzalez.

Quiz expôr os provaveis motivos que induziram o Senhor João Augusto Schmitt, a vender as suas eguas ao Senhor Gonzalez, se bem que para invocar o respeito de um contracto de compra-venda solemnemente estipulado perante um tabellião, não seja preciso demonstrar, quaes os motivos que induziram o vendedor a vender, e o comprador a comprar para affastar do animo de Vossa Excellencia qualquer sinistra impressão acerca de um contracto que não se reveste de forma alguma do caracter d'uma fraude, de uma simulação.

Quero pois acreditar que ninguem viesse a mente - nem menos ao Senhor Epiphanio Fogaça - a suspeita de que o contracto de compravenda estipulado aos 5 de Outubro de 1893, dez dias antes do sequestro das eguas, podesse ao contrario ter sido estipulado posteriormente ao mesmo sequestro. Isto é moralmente e materialmente inadmissivel. É moralmente inadimissivel, porque emquanto não existe uma condemnação de falso, sendo que o tabellião que estipulava semelhante contracto antedatado, não tenha sido processado, não é possivel acceitar uma tão grave suspeita; é inadmissivel materialmente, sendo que é sabido por todos, como os contractos feitos por intermedio de um tabellião, são registrados, numerados e collocados em protocollos, em ordem progressiva, e quaes sejam as formalidades estabelecidas pelas leis e pelos regulamento de todos os paizes, afim de impedir, para que um contracto não se dê uma data diversa da verdadeira e real. Em todo caso, junto a presente nota uma declaração do tabelião João de Oliveira Vianna que respeita a este ponto em questão (allegado $n^{0} 1$ ) 
Aqui juntos finalmente tenho a honra de transmittir a Vossa Excellencia (em copia), os documentos, os quaes provam que as eguas: Minerva, Venus, Aguia e Stella, quando foram vendidas pelo Senhor João Augusto Schmitt aos 5 de Outubro de 1893 ao Snr. Gonzalvez, pertenciam realmente ao Senhor juão Augusto Schmitt e não a outros.

Taes documentos são os que aqui se seguem.

Emquanto á egua "Minerva": a) existe um recido do Senhor Saturnino Mathias Velho, com data de 5 de Outubro de 1893, o qual claramente prova que a egua "Minerva" desde aquelle dia deixava de pertencer ao referido Senhor, o qual a vendia ao Senhor João Augusto Sckmitt (allegação $2^{a}$ ); b) uma declaração do Senhor Saturnino Mathias Velho, com data do mesmo dia, a qual novamente confirma, sob outra forma, a

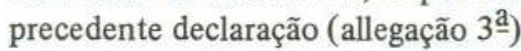

Quanto á egua "Venus": a) uma participação deixada pelo DiretorGerente do Prado "Rio Grandense", com data de 30 de Julho de 1892, com a qual certifica que a egua "Gravata" vinha inscripta sob o $n^{0} 162$ do Stud-Book Rio-Grandense, debaixo do nome de "Venus", como propriedade do Senhor Victorino Monteiro. (allegação 4a.). Confrontando-se as generalidades da egua descrita no livro do mesmo Stud-Book Rio-Grandense, com as generalidades da egua "Venus" descripta no contracto de compra-venda de 5 de Outubro de 1893 , vê-se bem que são as mesmas, e que trata-se do mesmo e identico quadrupede; b) uma declaração escripta em um cartão de visita, pelo qual resulta que o Senhor Bento Ribeiro, irmão do referido Dr. Victorino Monteiro, recebia em nome e por conta do proprio irmão, á 23 de Maio de 1893, a somma de réis $300 \$ 000$, pela dita egua (allegação 5a.). Convenho que este documento não tem a forma nem a importancia de um acto, como de tabellião, e nem tambem de um regular recibo; mas é notorio que taes contractos ordinariamente se costumam fazer assim, quando o preço da venda não é consideravel e quando os contratantes se confiam um no outro e se contentam com semelhante modo de prova.

Emquanto a egua "Aguia”: a) uma declaração do Senhor Saturnino Mathias Velho, da qual resulta que em data de 30 de Julho de 1893 recebia do Senhor José Antonio Cidade a somma de réis 1:000\$000, pela venda que lhe fazia da referida egua "Aguia" (allegação 6a.); b) uma declaração do Senhor José Antonio Cidade supra dicto, em data de 15 de Setembro de 1893 , donde resulta que n'aquella data elle vendia a egua "Aguia" ao Senhor João Augusto Schmitt, pelo valor de réis 1:500\$000 (allegação 7a.)

Finalmente quando a egua "Stella": a) um documento passado pelo Senhor Carlos Maria Villanueva em Buenos Ayres, aos 12 de Setembro de 1971 (allegação 8a.); b) uma declaração do Diretor-Gerente do Prado Rio-Grandense, com a qual certifica que a egua "Stella" foi inscripta na pagina primeira da Stud-Book "Rio-Grandense", sob n. ${ }^{0} 28$, como de 
propriedade de Senhor João Augusto Schmitt (allegação 9a.). É exato, repito que nem todos estes documentos tem valor probatorio, como de outros tantos documentos forenses, mas elles são mais que sufficientes, para provar que o Senhor João Augusto Schmitt antes da estipulação do documento exharado aos 5 de Outubro de 1893, pelo tabellião João de Oliveira Vianna, era o legitimo proprietario das eguas "Minerva, Venus, Aguia e Stella, desde o momento que ninguem o contesta e que os ex-proprietarios das eguas, mais vezes ditas, primeiro do que elle, estão promtos a testemunhar e jurar a mesma cousa.

O Senhor Intendente de São Leopoldo, no intuito de negar a todo trance a propriedade dos animaes reclamados pelo Senhor Gonzalez, allega que este Senhor nunca inscreveu nos Prados desta Capital animal algum, apresentando para dar valor a sua afirmativa dois certificados dos gerentes dos "Prados Rio-Grandense" e "Boa Vista", deixando muito de proposito de apresentar certificado do gerente do "Prado Navegantes", por, n'este Prado, ter corrido a egua "Stella" e sendo pago a premio de Rs $200 \$ 000$ ao Senhor Gonzalez, em 12 de Outubro de 1893, como consta da certidão junta (allegação 10a.).

Os outros documentos que este Regio Vice-Consulado teve a honra de transmittir a este Governo com a anterior correspondencia, acerca dos premios obtidos pelas eguas, de que se trata, não vinham citados, senão com o fim, de provar o valor real das mesmas eguas, especialmente de "Minerva".

Se com a minha nota de 5 de Fevereiro ultimo, incorri no erro de escrever que o Senhor Agapito Gonzalez considerava como devidas a elle tambem as quantias ganhas por "Minerva", no mes de Setembro de 1893 (quando aquella egua ainda não lhe pertencia); um tal erro se deve attribuir a uma inadvertencia. E digo unicamente isto, para poupar ao Senhor Epiphanio Fogaça o incommodo de abrir uma outra porta aberta e de demonstrar e repetir cem vezes que o Senhor Gonzalez não tem direito de exigir os premios ganhos pela "Minerva" ainda antes de lhe pertencer, como tem demonstrado e repetido cem vezes em sua afirmação de 12 de Fevereiro, ultimo findo, a saber: que um cavallo não é uma egua e que Minerva, Venus etc. são eguas e não cavallos.

Excellencia, de todos os precedentes manifestadamente apparece que o Senhor Agapito Gonzalez é victima d'uma verdadeira injustiça.

Emquanto os cavallos do Senhor Gonzalez - que e necessario repetir, é um honesto cidadão hespanhol, alheio a qualquer participação da politica do paiz, do qual honra a hospitalidade com o trabalho, com a boa conducta e com a caridade, - estão na posse de um tal Senhor Jacob Kroeff, do Senhor José Antonio Cidade e do Senhor José da Cunha; o Senhor Gonzalez prova com sufficiente contracto em seu poder que os cavallos são sua propriedade; mas não se quer attender nem aos documentos escriptos, nem ás declarações do Senhor Schmitt (pae), nem ás do 
Senhor João Augusto Schmitt (filho); nem ás do Senhor Saturnino Mathias Velho; nem do Senhor José Antonio Cidade; nem de ninguem; - unicamente presta-se attenção ás servis declarações do Senhor Epiphanio Fogaça, para perpetuar um estado de cousas que depois de tudo quanto tenho dito e demonstrado, estou em pleno direito de appellidar uma verdadeira comedia.

Appello para a honestidade de Vossa Excellencia, para que se digne remediar, e repito o pedido já feito e formulado pelo meu predecessor Marquez Leuciza Justiniano: isto é que sejam restituidas a seu verdadeiro e documentado proprietario, Agapito Gonzalez, as quatro eguas: Minerva, Venus, Aguia e Stella, e que lhe seja concedida uma justa e proporcionada indemnização pelos damnos tidos dos mesmos cavallos, e pelos prejuizos que o reclamante teve que soffrer por muitos mezes, não se podendo utilizar das suas eguas.

Pedido mais honesto do que este, não se poderia fazer.

O Governo não se pode recusar á restituição dos cavallos, desde que elles em nada prestam e não podem servir para os usos, pelos quaes fôram sequestrados, a saber: para urgente serviço do exercito. Nem tambem se pode recusar á indemnizar os damnos causados ao Senhor Agapito Gonzalez, pelo deterioramento dos cavallos e por ter-lhe impedido o uso dos mesmos por tantos mezes, sendo que assim dos damnos, como da não effectuada restituição é responsavel o Governo.

Reduzida a estes termos a demanda, me e impossivel comprehender, como o Senhor Fogaça ouse fallar de uma sordida especulação, com a qual pretende-se assaltar os cofres publicos, á sombra de uma bandeira estrangeira. Mas de graça o que poderia demandar de menos o Senhor Gonzalez? não é mais que evidente que o caso do Senhor Gonzalez induzirá os governos européos, a fazer as mais amargas reflexões? Acerca da sorte que aguarda tantos pobres colonnos e commerciantes, aos quaes foram sequestrados: cavallos, mulas, vaccas, bois e outros animaes, e aos quaes não fôram deixados documentos alguns, ou documentos incompletos e imperfeitos? Se ao Senhor Agapito Gonzalez, conhecido pela sua honestidade, rectidão e beneficencia, pela sua conducta exemplar, e exemplar respeito ao paiz que lh'a dá hospitalidade; se ao Senhor Gonzalez, munido de toda sorte de documentos probatorios, avigorado pelo testemunho dos mesmos que teriam interesse em depôr em seu prejuizo, acontece o que está acontecendo, o que será de tantos reclamantes que não podem contar sobre algumas de taes vantagens, ou sobre poucas somente? Quaes são as garantias que os Governos deverão tomar, para impedir que os seus connacionaes sejam tão duramente sacrificados?

Confio que não será necessario remetter esta pratica ás mãos da Legação hespanhola em Rio de Janeiro e do Governo de sua Magestade Catholica em Madrid, e que Vossa Excellencia - em virtude de vossa sabedoria, benevolencia e justiça - se dignará tomar uma medida igual- 
mente satisfactoria para todos, na persuação de que este Regio Vice-Consulado metterá em obra todo o espirito d'uma conciliação possivel.

Aproveito esta occasião, para apresentar a Vossa Excellencia as provas da minha mais subida consideração.

\author{
O Consul interino \\ encarregado da direção do \\ Vice-Consulado d'Hespanha \\ Gherardo Pio de Savoia
}

R. Vice-Consulado de España

Porto Alegre, 12 de Giugno 1894

№ 24

\title{
Eccellenza
}

Mi onoro di trasmettere qui unita all' Eccelenza Vostra copia autentica di um reclamo presentato dal suddito spagnuolo Benigno da Cunha per sequestro di un cavallo del valore di Rs. $300 \$ 000$.

Esprimendo la sperenza che la Commissione che deve procedere alla verificazione dei danni per furti e sequestri di animali inconninci presto i suvi lavori, in modo saddisfaccente per tutti, sicuro della rettitudine delle intenzioni dell' Eccelenza Vostra e piemamente fiducioso nelle promesse solenni che Ella ha fatte, la prego, Sig. Presidente, di gradire la espressione del mio profondo rispetto.

II Consule

Incaricato della direzione del

Real Vice Consolato di Spagna

Gherardo Pio de Savoya
A Sua Eccelza
H. D? Julio Prates de Castilhos
Presidente dello Stato di Rio
Grande del Sul
Capitale 


\section{Copia}

IIl ${ }^{\text {mo }}$ Senr̃. Representante da Nação Hespanhola perante o Governo Brasileiro.

Louvado no direito que me assiste a lei, venho a presença de V. S. queixar-me, se não de uma violencia por parte de ajentes do Governo, junto ao qual V. S. é muito digno representante, pelo menos de um desrespeito ao direito que protege ao Cidadão estrangeiro.

Pertencendo como provo com documento junto a Nação hespanhola, do que muito me orgulho, e a qual V.S. tão sabiamente sabe fazer respeitar, acredito não poupará esforços afim de que os subditos de V. S. não saffra, não são nas suas individualidades como nos seus interesses: é no ultimo sentido que imploro a V.S.; pois acabam de obrigar-me forças do Governo legal a entrega de um cavallo de minha propriedade, o qual conservava em trato; dizendo-me elles nesta occasião: que não sendo os estrangeiros obrigados ao serviço Nacional, era justo que seus interesses soffressem, e sendo o queixoso creador em pequena escala, receia a reprodução de semelhante abuso, e para que assim não acconteça trago as mãos de $\mathrm{V}$. S. a presente reclamação assignada e testemunhada.

Municipio de Rio Pardo, 4 de Junho de 1894

$$
\begin{aligned}
\text { firmado } & =\text { Beninho da Cunha } \\
“ \quad & =\text { José Joaquim Duarte } \\
“ \quad & =\text { João Alexandre Flores } \\
“ \quad & =\text { José Francisco da Rosa }
\end{aligned}
$$

Visto $=$ per copia conforme all originale conservado in atti.

Porto Alegre 12 Giugno 1894

$$
\text { Il Consule }
$$

Incaricato della direzione del

Real Vice-Consolato di Spagna

Gherardo Pio de Savoya 
№ 24 Regio Vice-Consulado d'Hespanha

Porto Alegre, 12 de Junho de 1894

\section{Excellencia}

Tenho a horna de transmitir a Vossa Excellencia, junto a este, uma copia authentica de uma reclamação apresentada pelo subdito hespanhol Benigno da Cunha sobre o roubo de um cavallo, no valor de $300 \$ 000$ rs.

Nutro a esperança de que a comissão que deve proceder á verificação de damnos por furtos e sequestro de animaes iniciará em breve os seus trabalhos, de maneira satisfactoria para todos, seguro da rectidão de intenções de V. Excellencia e firmemente confiado nas promessas solemnes que haveis feito.

Peço-vos, Sr. Presidente, aceiteis a expressão do meu profundo respeito.
A. S. Exa. o Dr. Julio Prates de Castilhos, Presidente do Estado do Rio Grande do Sul Capital

O Cunsul encarregado da direção do Real Vice-Consulado d'Hespanha.

Gherardo Pio de Saboya

$\mathrm{N}^{0} 26$ Real Vice-Consulado d'Hespanha

Porto Alegre, 19 de Junho de 1894

\section{Excellencia}

Não havendo ainda recebido resposta alguma á minha nota de 30 de Maio proximo passado, referente ao sequestro dos cavallos do sr. Agapito Gonçales, acho-me na necessidade de tornar a reclamar a attenção de Vossa Excelencia sobre a gravidade desta questão - gravidade que tende a augmentar diante do silencio do Governo, que não quer reconhecer as razões expostas por Gonçalves, nem tomar em consideração os documentos exhibidos, nem emfim adduzir mesmo outros documentos e outras razões em contrario.

Vossa Excellencia, em nota de 20 de Abril proximo findo, n. 791, assegurou-me solemnemente haver dado novas instrucções a seus subalternos para informar-se melhor dos factos, objecto da reclamação, e para fazer com base a devida justiça; mas parece bem que taes instrucções, ou não forão dadas, ou não forão tomadas em obediente consideração.

Vossa Excellencia, de viva voz, me ha prometido mais de uma vez, não me deixar partir desta cidade sem primeiramente dar-me conhecimento das decisões 
do Governo sobre a reclamação do sr. Agapito Gonçalves; mas - ainda assim acho-me na vespera da partida sem que Vossa Excellencia tenha tomado qualquer determinação.

Eu não posso admitir isso, que se vae murmurando, que os interesses da justiça sejão, desta vez, sacrificados aos da politica e que os cavallos do sr. Agapito Gonçalves devão servir para pagar os serviços de qualquer zeloso servidor: repillo tal insinuação; Vossa Excellencia, porem, deve concordar comigo em que, se, depois de tanto tempo, o Governo não tem conseguido provar - apezar de todos os meios de que dispõe - que a pretenção do sr. Agapito Gonçalves é infundada, ha motivo para se murmurar e fazer as hypotheses menos lisongeiras.

Nada mais podendo fazer, informei a Real Legação d'Hespanha, no Rio de Janeiro, sobre o estado actual de questão e me lisongeio de que o appello que meu sucessor tenha de fazer á justiça e á rectidão de Vossa Excellencia seja acolhido melhor do que o foi o meu, certamente por minha propria culpa.

Com profundo respeito

Gherardo Pio de Saboya

A. S. Exa. Dr. Julio Prates de Castilhos,

Presidente do Estado do Rio Grande do Sul

R. Vice-Consulado de España

No 26

Porto Alegre, 1ํㅡㅁ Giugno 1894

\section{Eccelenza}

Non avendo ancora ricevuta alcuna risposta alla mia nota del 30 Maggio n. s., № 21, concernente il sequestro dei cavalli del Sig. Agapito Gonçales, mi trovo nella necessitá di tornare a richiamare l'attenzione dell'Eccellenza Vostra sulla gravitá di questa questione - gravitá che non puó che aumentare di fronte al silenzio del Governo che non vuol riconoscere le ragioni presentate dal Gonçalves, ne'tener conto dei documenti esibiti ne'infine produrre esso stesso altri documenti ed altre regioni in contrario.

L'Eccellenza Vostra colla nota del 20. Aprile n. s., № 91, mi ha solennemente assicurato di aver date nuove istruzioni ai suoi subalterni per chiarire meghio i fatti, oggetto del reclamo e per potere fare in base ad esse la dovuta giustizia, ma purtroppo sembra che tali istruzioni o non siano state date o non siano state prese in obbediente considerazione.

A voce, l'Eccellenza Vostra mi ha anche promesso, piu'di una volta di non lasciarmi partire da questa cittá senza prima farmi conoscere le decisioni del Governo circa il reclamo del Sig. ${ }^{\mathrm{r}}$ Agapito Gonçalves ma - purtroppo anche qui - io mi trovo alla vigilia della partenza senur che l'Eccellenza Vostra abbia presa alcuma determinazione. 
Io non posso ammettere, ció che si va susurrando che gl'interessi della giustizia siano questa volta sacrificati a quelli della politica e che i cavalli del Sig. Agapito Gonçalves debbano servire a pagare i servini di qualche zelante servitore; io respingo una tale insinuazione; l'Eccllenza Vostra pero' deve ammettere con me, che, se dopo tanto tempo il Governo non é rinscito a provare - malgrado di tutti i mezzi di cui dispone - che le pretese del $\mathrm{Sig}^{\mathrm{r}}$. Agapito Gonçalves sono infondate, si ha ragione di mormorare e di fare le ipotesi meno lusinghiere.

Non pretendo far altro, ho informato la R. ${ }^{\mathrm{a}}$ Legazione di Spagna in Rio Janeiro dello stato attuale della questione e mi lusingo che l'appello che il mio successore fará alla giustizia ed alla rettitudine dell'Eccellenza Vostra possa vemire ascoltato piú di quanto lo fu il mio, certamente per colpa de me stesso.

Con profondo rispetto

\section{Derno}

Gherardo Pio di Savoya

Vice Consulado de Hespanha

Rio Grande, 20 de Abril de 1894

$$
\mathrm{Ex}^{\mathrm{mo}} \text { Senhor }
$$

Accuso o oficio de V. E. datado de 9 do actual, communicando-me que, em virtude do que determinou S. E. o Snr Ministro das Relações Exteriores, em telegrama de $1^{\mathrm{O}}$ do corr., espeilio n'esta data ordens para o meu reconhecimento no cargo de Vice-Consul de Hespanha, n'esta cidade.

Cumpre-me penhorado agradecer a V. E. tal communicação, na certeza que farei no desempenho do cargo, tudo quanto for á bem do serviço que me foi confiado, e certo de merecer a confiança de V. E. approveito a occasião para appresentar a V. E. os meus maiores respeitos e considerações.

Ả S. E. o Snr. D ${ }^{\text {or }}$ Julio de Castilhos

Muito D. Governador do Estado

Florencio Rodrigues

Vice Con. sub. 


$$
\mathrm{Ex}^{\mathrm{mo}} \mathrm{Sr}
$$

Con fcha 28 de Febrero ppdo, he tenido el honor de recivir el oficio de V.E. que me participaba haber impartido las órdenes necesarias para que fue se reconocido en esta ciudad y su Municipio, como Vice Consul interino de España.

Tengo la honrra de adjuntar a esta Comunicacion, el Exequatur que con fcha 15 de Mayo se ha servido enviarme el Ex ${ }^{\mathrm{mo}}$. Sr.Presidente de la República, confirmando la propriedad del mismo Cargo.

Si V.E. tubiese por conviniente hacer me acreditar ante el Estado que dignamente Preside, en tal caracter, desearia se dignase autorizar las diligencias necesarias.

D.G. V.E m. a.

San Borja Setiembre 1. 1894

\section{Eduardo Ogayan}

Ex. ${ }^{\text {mo }}$ Sr. Presidente Del Estado de

Rio Grande del Sud

Porto Alegre, 10 junho 1895

A.S. Exia el Sñr $D^{\mathrm{r}}$ Don Julio de Castilhos

M.D. Presidente de este Estado

$$
\text { Ex cia }
$$

Tengo el honor de junto a estas remitivos por copia la solicitud del sudito español, Vicente Font Santa Maria, que segun el afirma fue reclutado en el Estado de S. Pablo, y hoy se halla sirviendo contra su voluntad en la Milicia de este Estado. No puede este Vice-Consulado conocer lo que hay de verdad en la solicitud de dicho español, asi espera

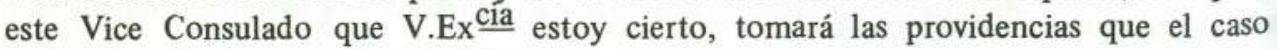
reclama, y obrará con entera justicia. ración

Me es grato reiteiravos Sñr Presidente, los protestos de mi mayor estima y conside-

Dios guarde V.Ex. muchos años

El encaregado del Vice-Consulado

El encaregado del Vice-Consulado 
Copia do documento anexo - de 10 de junho de 1895

Vice Consulado de Porto Alegre

\section{Snr Consul de España}

Vicente Font Sant Maria; Sargento primero del 3. Batallón de la Brigada Militar, siendo natural de Valencia perteneciente a la nacion que tan dignamente representais, viene respetuosamente comunicavos que en Noviembre de 1893 fue reclutado por la Guardia Nacional de S. Pablo y en 22 de dicho mes sali de aquel lugar con dirección al Estado do Paraná donde llegamos el dia 14 de Enero al punto denominado Paranaguá, que despues de um combate con los federalistas, fué aprisionado por estos el dia 15 de donde desertando y marchando para este Estado, vine a recoferme con este Batallón y y le filiaron por 5 años, no existiendo documento alguno de yo haber contraido compromiso, y como quiera que me hallo sirviendo constrangido y teniendo noticias que hay una orden vigente que declara que extrangero no está obligado a servir, cuya orden ignoro la dacta, pidole por tanto proteccion a fin de salir de la Milicia.

Porto Alegre 6 de Junio de 1896. (Firmado / Vicente Font Santa Maria conforme

El encargado del Vice-Consulado

\section{Agapito Gonzales}

A. A. Exo.

\section{Exmo Sr}

Tengo en mi poder los reclamos que me dirigen los Cidadanos Españoles en pleno goce dela proteccion Consular, sacrificados por los revolucionarios durante su última y honorosa permanencia en esta Region.

Impresiona vivamente Exm̃o Sr, la situacion penosa en que se encuentran, sin Causa ninguna que justifique el robo de sus sagrados interesses comerciáles.

Es muy proverbial en la persona de V.E., los altos sentimientos de justicia y benevolencia que lo distinguen, y por eso y en cumplimiento de mi deber, desearia que V. E. se dignase manifestarme al respecto lo que jurgue conveniente.

D. G.V.E. $\mathrm{m} \underline{\mathrm{s}}$ as

San Borja Enero 2 de 1895.

Eduardo Ogayan

Exmo Sr Presidente del Estado de Rio Grande del Sud en Porto Alegre. 
Copia vice consulado de Hespanha em S.Borja $=\mathrm{Ex}^{\mathrm{mo}} \mathrm{Snr}=$

Incluyo a este un expediente que el cidadano Españhol Sr Martin Ians me ha presentado para elevar al Gobierno de S E por intermedio deste S. Consulado para los fines a que haya lugar $=$ me permito esperar de $\mathrm{S}$ E se digne mandar acusar $\mathrm{mi}$ recibo y manifestarme el despacho que mereça en reclamacion de mi representado

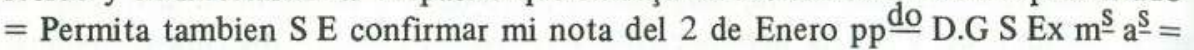
S. Borja marzo 23, $1895=$ Eduardo Ogajar $=$ Exm̃o Sr.Presidente del Estado de Rio Grande del Sud, Porto Alegre.

Conforme

O Director Geral

Aurelio Virissimo de Bittencourt

Exm $^{\mathrm{O}}$ Snr' $\mathrm{D}^{\mathrm{r}} \mathrm{D}^{\mathrm{n}}$ Julio de Castilhos D. Presidente do Estado

Ex cia

Confirmo mis notas de 26 de marzo $\mathrm{pp}^{\mathrm{o}}$ y del mes que cursa.

$$
\text { Ex cia }
$$

En vuestra nota $n^{0} 1284$ de 12 de Setiembre de 1894, declaraisteis a este Vice-Consulado de España, haber pedido imformes al General Antonio Adolfo da Fontoura Mena Barreto, sobre el sequestro de (un) cavallo de propriedad del subdito español; Benigno Cuñas, de que trató, la nota de este Vice-Consulado, $\mathrm{n}^{0} 24$ de 12 de Junio del año de 1893, y como hasta hoy no tenga este Vice-Consulado recebido solucion, alguna, pido a V. G. una solucion, para hacer la llegar a manos del reclamante.

Pidiendoos $\operatorname{Exm}^{\circ}$ Snr' acuseis recibo de esta me es grato reiterarvos las espresiones de mi profundo respeto y consideracion.

Dios Guarde a V. E. ms años.

Porto Alegre 10 de Abril 1895

El encargado de Vice-Consulado 
A S. Excia. el Smr̃. Dr. Dn. Julio de Castilhos

M. D. Presidente del Estado

\section{Excia.}

A este Vice-Consulado se presentó el sudito español Ramon Castilhos, domiciliado en la colonia "Barão do Triupho" quejandose contra el acto insolito del Sm̃r Intendente de San Jeronimo que segum dice sin la mas pequeña rajon lo castigo vilmente en la mejilla.

Como V. Excia. comprende este echo que podia traer funestos resultados, practicado por una autoridade que tiene a su alcance todos los medios que las leyes facultan para hacerse respetar, a ser cierto como espara este Vice-Consulado, y V. Excia. averiguara, merece un serio corretivo y este Vice-Consulado espera de V. Ex $\stackrel{\text { cia }}{\text { las providencias }}$ necesarias.

Aprovecho Sĩr Presidente la oportunidad, para reiterar a V. Ex $\stackrel{\text { cia }}{-}$ los protestos de mi mas alta consideracion y estima.

Dios guarde a V. Excia. muchos años.

Porto Alegre 12 setiembre 1895.

El encargado del Vice-Consulado

Agapito Gonzalez

A S.Ex cia el Sñr Doctor Don Julio de Castilhos

M.D. Presidente del Estado

Ex $\underline{\text { cia }}$

Con fecha 12 del mes p p do, este Vice-Consulado, tuvo la honra de dirijirse á V.E. ponendo en vuestro conocimiento la queja presentada por el sudito Español Ramom Castilhos, contra el Sñr Intendente de S. Jeronimo, queja esta que hoy por copia tengo el honor de pasar a vuestras manos, mas como hasta hoy no haya tenido solucion alguna, de nuevo este Vice-Consulado pide a V.E. poner un paradero a tales desmanes, pues hoy acrece mas, que debido presecuciones injustas se halla refujiado en esta Capital Antonio Castilhos padre del quejose que segun espone verbalmente serve en la necessidad de abandonar su familia y trabajo para no sufrir la afronta que sufrió su hijo. 
Este Vice-Consulado en la jus del Gobierno de V.E. espera, una pronta solucion, que leve la calma al seno de una familia,onesta y trabajadora, hoy atribulada, con su jefe ausente y aciendo gastos que sus fuersas no le permiten, por no contar con el apoyo que la ley le concede y que las autoridades parece le niegan.

Al pedivos Sñr Presidente acusar recibo de la presente, me es grato renovavos los protestos de mi mas dintinguida estima y consideradion

Dios Guarde a V.E. muchos años

Porto Alegre 15 Octubre 1895

El encargado del Vice-Consulado

Agapito Gonzalez

Copia

Sñr Don Agapito Gonzalez - Muy Sñr mio; pongo en su conocimiento los abusos que ocurren en esta Colonia; Yendo yo á la sede hablar con el sub intendente da dicha Colonia; respecto de que mi padre no podia subir por causa de estar malo, yo le pregunté, para que lo mandava llamar, y me contestó que hera para pagarle los bueyes, yo contesté que como no havia matado ninguno no tenia que pagar nada y tuvo el atrevimiento de darme una bofetada en la cara. El Sñr como defensor nuestro haga por favor de defender esta causa.- Dios guarde a V. muchos años.

Colonia Baron do Triunpho 8 de Setiembre 1895 (Firmado)

Ramon Castillo

Esta conforme

El encargado del Vice Consulado

Agapito Gonzalez

Porto Alegre 25 setiembre 1895 
A S. Ex ${ }^{\text {cia }}$ el Sñr Doctor Don Julio de Castilhos

M.D. Presidente del Estado

$$
\text { Ex }{ }^{\text {cia }}
$$

Este Vice-Consulado tiene el honor de acusar recibo del oficio de esa presidencia de 21 del mes que cursa aompañando copia de la informacion del Sñr Intendente de S.Jeronimo sobre la queja que dió lugar a los oficios de este Vice-Consulado de 12 de Septiembre y 15 del que cursa; informacion esa que despues de leida con toda atencion, veo con pesar, que, o este Vice-Consulado fué engañado, o el Sñr Intendente cambiando nombres e personas quiere sacar la custión de su verdadero terreno, como paso á esponer:

Este Vice-Consulado fué informado verbalmente y por diversos individuos que habiendo sido hallado muerto (o prouximo a morir) un buey que por el rastro de sangue parecia haber salido de las tierras de labor de colono español Antonio Castilhos; que las autoridades locales de la colonia "Barão do Triunpho" sin que el hecho fuese provado por el testimonio de vista de persona alguna y por simple sospecha del ya mencionado rasto, culpaban como autor al citado colono y sin mas forma de proceso,sin dar lugar a defensa, fue intimado a pagar la cantidad de $120 \$ 000$ reis por el animal muerto, alo que negose el colono, declarando no haber conetido el hecho que se imputava.

Por lo expuesto claramente se deduce que si delincuente hay, puede ser Antonio Castilhos y no Ramon Castillos y como el que recibio el mal trato fue este y no aquel, conforme copia de la queja que envié a V.E. junto con el oficio de este Vice-Consulado de 15 del que cursa.

Esperava este Vice-Consulado de la justicia de V.E. otra solucion, por no poderse conformar con la dada por la información disculpa del Sñr Intendente de S.Jeronimo, deplorando tener que llevar esta ocurrencia al conocimiento de S.Ex. el Sñr Ministro de España en Rio de Janeiro esperando instruciones sobre tan delicado asunto.

Renuevo al Snr Presidente com el mayor afecto los protestos de mi mas alto aprecio y consideracion

Dios Guarde A V.E. muchos años

Porto Alegre 22 Octubre de 1895

El encargado del Vice- Consulado

Agapito Gonzalez 


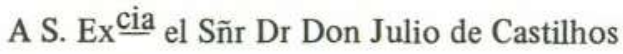

M. D. Presidente del Estado

Ex $\underline{\text { cia }}$

Es grato a este Vice-Consulado acusar recibo del esemplar de la mensage dirigida por V. E. a la H. Ascemblea de los Representantes del Estado, en el corrient año.

A agradecer a V.E. el envio de tan valioso documento istorico, me es grato renovaros los protestos de mi mas distinguida consideration

Dios Guarde a V. E. m. años

Porto Alegre 24 Novembre 1895

El encarregado del Vice-Consulado

Agapito Gonzalez

A S. EX ${ }^{\text {cia }}$ el Sñr Doctor Don Julio de Castilhos muy Digno Presidente del Estado.

$$
\text { Ex cia }
$$

Tengo la honra de lleva á vuestro conocimento que teniendo que reiterarme temporariamente de esta Capital queda respondendo por este Vice-Consulado el sudito español Don Agustin Fernandez a quien en esta fecha paso el encargo.

Renuevo a V. E. los protestos de mi mas distinguida consideración.

Dios Guarde á V.E. m. a.

Porto Alegre, 29 de Junio de 1897.

El encargado del Vice-Consulado 
A S.Ex ${ }^{\text {cia }}$ el Snr $D^{\mathrm{r}}$ Don Julio de Castilhos

M.D. Presidente del Estado

$$
\text { Ex cia }
$$

Tengo la subida honra de comunicavos que en esta fecha reasumi la direcion de este Vice-Consulado, lo que me apresuro a llevar á el conocimiento de V.E., para los debidos fines.

Mas una vez reitero á V.E. los protestos de mi mas profunda consideracion.

Dios Guarde a V.E. m. a.

Porto Alegre 20 de agosto 1897

\section{Agapito Gonzales}

A S. Ex ${ }^{\text {cia }}$ el Sñr Desembargador

$D^{r}$ A. A. Borges de Medeiros

Presidente del Estado

$$
\text { Ex } \underline{\text { cia }}
$$

Ausente de esta Capital en cumplimiento de ordenes superiores, solo en 23 de este mes binome a las manos vuestro oficio circular de 25 de Enero en el que me comunicais haber asumido la Presidencia del Estado.

Este Vice-Consulado se apresura a felicitavos por la alta deferencia que octuvisteis de vuestros concindadanos elevandoos a tan honroso cargo.

Approvecho tan grata oportunidad para agradecevos tan honrosa comunicación, y pressentavos los protestos de mi mas alta estima y consideración.

Dios Guarde a V.E. m. a.

Porto Alegre 25 Febrero 1898

El encargado del Vice-Consulado

Agapito Gonzalles. 


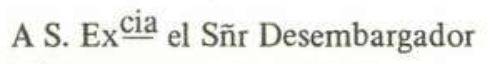

$\mathrm{D}^{\mathrm{r}}$ A. A. Borges de Medeiros

M. D. Presidente del Estado.

$$
\text { Ex } \stackrel{\text { cia }}{\underline{4}}
$$

El estado de penuria en que por falta de trabajo se hallan los peticionarios de la solicitud que remetí a V.E. con el oficio de este Vice-Consulado fecha 2 del corriente me hace pedirvos una solucion, a fin de transmitirla a los peticionarios que diariamente vienen a este Vice-Consulado, a fin de saber el resultado.

Cierto que V.E. atenderá el pedido de estos desprotejidos, tengo satisfaccion en reiteravos los protestos de la mas alta estima y consideracion.

Dios Guarde a V.E. muchos años.

Porto Alegre 18 abril 1898

El encargado del Vice-Consulado

Agaṕito Gonzalles.

26 outubro 1898

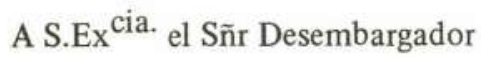

$\mathrm{D}^{\mathrm{r}}$ Antonio Augusto Borges de Medeiros

M. D. Presidente del Estado.

$$
\text { Ex } \stackrel{\text { mo. }}{\text { Sñr }}
$$

Es grato a este Vice-Consulado acusar recibo del esemplar de la Mensage por vos dirigida a los representantes del Estado, por ocasión de la apertura de sus trabajos, en 20 de Setiembre del corriente año.

$\mathrm{Al}$ agradecevos tan valioso documento histórico, me es grato renovavos los protestos de mi mas alta consideración y estima.

Dios Guarde a V.E. m. a.

El encargado del Vice-Consulado

Agapito Gonzalles. 


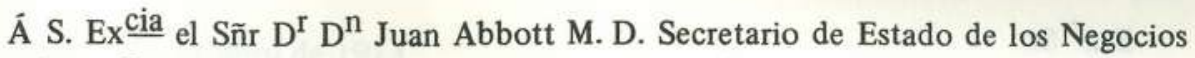
del Interior y Esterior

\section{Ex $\stackrel{\text { mo }}{=}$ Sñr}

Es grato a este Vice-Consulado, acusar recibo de vuestro oficio fecha 23 del que vige, con el que vos dignaisteis remetir 2 esemplares del relario por vos pressentado al Ex ${ }^{\mathrm{mo}}$ Sñr Presidente del Estado, en 30 de Julio del corriente año.

$\mathrm{Al}$ agradecevos tan valiosa remesa, devo felicitavos por la forma altamente honrosa $\mathrm{e}$ inteligente, conque dirigis la Secretaria que en buena hora os fuí confiada.

Aprovecho tan grata oportunidad para presentavos los protestos de mi mas alta consideración.

Dios Guarde á V.E. m. años

Porto Alegre 30 Noviembre 1898

El encargado del Vice-Consulado

Agapito Gonzalles.

Á Su Ex ${ }^{\text {cia }}$ el Sñr D ${ }^{r}$ Don A. A. Borges de Medeiros m. D. Presidente del Estado.

$$
\text { Ex } \underline{\text { cia }}
$$

Hayer se presento a este Vice-Consulado el sudito español Gines Sanchez, vindo, acompañado de tres hijos menores en estremo estado de pobreza, y por los documentos presentados provó que, por intermedio del $\mathrm{Exm}^{\mathrm{O}}$ Sñr Ministro de España, octuvo pasage á fin de trasladarse a este Estado, á fin de reunirse á su familia residente em S'antanna do Livramento; hallandose el citado Sanchez sin recurso, ruego a V.E. octener de la Comp ${ }^{\text {a }}$ arrendataria del camino de fierro de P.A. a Uruguayana pasage asta la estación mas prouxima de su destino para estos desprotegidos de la fortuna.

Cierto que el magnammo corazón de V.E. no dejará de atender este reclamo de la desgracia, aprovecho la oportunidad para reiterar á V.E. los protestos de mi mas distinguida consideración.

Dios Guarde V.E. m. años

Porto Alegre 15 marzo 1899

El encargado del Vice-Consulado

Agapito Gonzalles. 
$\mathrm{Exl}^{\mathrm{O}} \mathrm{Sr}$.

D. Protasio Alves

Muy $\mathrm{S}^{\mathrm{or}}$ mío.

Sigo gustoso el honroso deber de la anunciacion de la recepción del oficio n 0432 fecha 25 Enero del corriente año.

En el cual me comunica tener asumido el cargo de Secretario del Estado. Acepta pues V.E. cordiales felicitaciones de este Vice-Consulado, al cual con la merecida consideracion reitame los protestos de su mayor Apreso.

Dios Guarde V.E. muchos años

\title{
Porto Alegre 4 marzo 1913
}

José Salvador

Vice Consul de España

Vice- Consulado de España

Porto Alegre

Oficio $n^{\circ} 152$

Exl $\stackrel{\text { mo }}{=}$ Sr. D ${ }^{\text {or }}$ A. A. Borges de Medeiros

M. D. Presidente del Estado

Sigo gustoso el honroso deber de la anunciacion la recepcion del odicio $\mathrm{n}^{\mathrm{0}} 152$ fecha del 25 Enero del corriente año en el cual me comunica haber asumido el cargo de la presidencia del Estado.

Acepto pues V. E. cordiales felicitaciones de este Vice-Consulado el cual con la merecida consideracion reiterarla los protestos de su mayor aprecio.

Dios Guarde a V. E. muchos años.

\author{
José Salvador \\ Vice-Consul Interino
}




\title{
Excellencia:
}

Tenho a subida honra de levar ao conhecimento de V.E. que por ordem de S.E. o Senhor Ministro Plenipotenciario da Hespanha acreditado perante o Governo do Brazil, estou exercendo interinamente o cargo de Vice Consul da Hespanha n'esta Capital.

Julio Bozano.

Vice Consul Interino.
A S.E. o Exmo Senhor Dr. Antonio Augusto Borges de Medeiros
M. D. PRESIDENTE do ESTADO do RIO GRANDE do SUL N/C.

Porto Alegre 11 do julho 1924

\author{
Excmo. Senhor Dr. EURIBYADES DUTRA VILLA \\ M. D. CHEFE de POLICIA do Estado.
}

Chegando no dia 13 do corrente com o vapor "Itapuca" minha família, ficarei muito grato a V.S. se for possivel conceder-me a devida licença, para poder ir a bordo do mesmo vapor antes de ter atracado ao caes. Sendo minha esposa com a filha desejava auxilial-as no desembarque e para evitar o extravio de alguma malinhas de mão.

Ficando desde já agradecido, aproveito a opportunidade para reiterar a V.S. Illma. os protestos de minha mais alta e consideração.

Julio Bozano

Vice Consul de Hespanha 